\title{
Estratégias de repredicação de referentes e progressão temática do texto
}

\author{
Heliud Luis Maia Moura \\ Universidade Federal do Oeste do Pará (UFOPA), Santarém, Pará, Brasil \\ heliudlmm@yahoo.com.br
}

DOI: http://dx.doi.org/10.21165/el.v46i3.1516

\begin{abstract}
Resumo
Meu objetivo, neste artigo, é analisar estratégias de repredicação de referentes em narrativas afiliadas ao universo do lendário da Amazônia, compreendendo quatro personagens: Boto, Cobra, Matintaperera e Curupira. Tais estratégias constituem recursos de natureza textual-discursiva que encampam processos sociocognitivos e cognitivo-culturais, os quais estão na base da construção dessas narrativas e que servem de instrumentos para seu entendimento, considerando o próprio contexto social de sua produção e circulação. De acordo com as hipóteses levantadas, meu propósito consiste em investigar as formas de repredicação das mencionadas entidades, considerando o modo como a progressão temática do texto se constrói a partir dessas repredicações. Tomo como referencial teórico as postulações de Koch $(2004,2006,2008)$, Marcuschi (2007, 2008) e Mondada e Dubois (2003).
\end{abstract}

Palavras-chave: referenciação; repredicação; progressão temática.

\section{Repredication strategies references and thematic progression of the text}

\begin{abstract}
My goal, in this article, is to analyze repredication related strategies in narratives associated to Amazon legendary universe, comprising four (4) characters: Boto, Cobra, Matintaperera and Curupira. Such strategies are resources of textual-discursive nature including socio-cognitive and cognitive-cultural processes that underlie the construction of these narratives and serve as tools for their understanding, considering the very social context of their production and circulation. According to the hypotheses suggested, my purpose is to investigate ways of repredication of the mentioned entities, considering how the thematic progression of the text is constructed from these repredications. I take as the theoretical reference the assumptions of Koch $(2004,2006,2008)$, Marcuschi $(2007,2008)$ and Mondada and Dubois (2003).
\end{abstract}

Keywords: referral; repredications; thematic progression.

\section{Introdução}

Segundo Marcuschi (2007), a língua constitui-se como um conjunto de práticas sociointerativas, de tal sorte que os efeitos referentes à codificação e à estandardização não são os seus únicos elementos definidores. Tal característica leva-nos a concluir que a calibragem de nossos enquadres cognitivos não vem somente da exterioridade sociohistórica, mas também dos efeitos de continuidade entre sociedade e cognição, em outras palavras, de uma espécie de clivagem sociocognitiva. De acordo com o autor (idem), o modo como nós referimos as coisas aos outros é fruto de nossa atuação linguística sobre o mundo por meio da língua, de nossa "intromissão" sociocognitiva nos espaços biossociais e culturais, nos quais emergem conhecimentos de diversas esferas. 
Nesse sentido, a experiência não constitui um dado puramente imanente, mas se apresenta com uma construção cognitiva, em que a percepção não acontece diretamente com os componentes sensoriais constitutivos do ser humano, mas é resultante de reorganizações ou reconstruções das sensações primárias ampliadas e ressignificadas quando do contato do indivíduo com os mais diferentes espaços interativos.

Dado o exposto, ainda na esteira do autor, o mundo comunicado é produto de uma ação cognitiva e não de um puro reconhecimento de realidades discretas apreendidas de forma direta. Assim, a realidade biossociocultural constitui um contínuo de impressões sensoriais e a realidade do mundo empírico não possui um contorno diretamente apreensível. Logo, o ato de discretizar o mundo na maneira como o referimos é um trabalho sociocognitivo contínuo, sistemático. Dada essa concepção, a ação de repredicar reside em um processo por meio do qual avaliamos os diversos referentes do mundo social, de modo que construímos posições acerca destes, assim como os reconstruímos enquanto objetos de discurso ${ }^{1}$. A repredicação ${ }^{2}$ passa a atuar então como resultado de processos sociocognitivos emergenciados pelos contextos em que a língua se manifesta. É, portanto, uma atividade dinâmica de "reelaboração" de características de referentes em jogo nas interações. Também constitui um processo por meio do qual dizemos coisas acerca dos referentes do universo cultural, de modo que tais referentes passam a ser constantemente reconstruídos. Pode-se dizer, então, com base no conceito de repredicação, que nossas versões acerca do mundo estão sendo sempre reconstruídas, perenemente reavaliadas, sendo, por conseguinte, provisórias, praxeológicas e não tomadas como construtos naturais. Por este viés, a linguagem é uma ação constitutiva e não um instrumento de representação da realidade. Mais que um espelho do mundo, a língua é um processo infinito por meio do qual tratamos a realidade.

Considerando a importância das atividades de repredicação de referentes no processo de construção dos textos orais e escritos, postulo a favor da noção de que essas atividades se apresentam como essenciais e não somente como contigenciais na tarefa de (re)construção dos mais variados objetos de discurso em circulação nos mais diferenciados espaços interacionais. No curso da progressão temática do texto, os referentes passam a ser requalificados, extendidos, renomeados, assim como reidentificados na forma como suas ações configuram a própria progressão textual em termos do que denomino de "coerência tópica" no processo de construção da atividade narrativa.

As narrativas que integram o corpus em análise, relativas aos personagens lendários Boto, Cobra, Matintaperera e Curupira, constituem um conjunto ou acervo representativo dentro de uma ampla variedade de histórias que são contadas no interior da Amazônia. Essas narrativas são produções ficcionais escritas e manifestam uma maneira particular, do escritor paraense Walcyr Monteiro, de conceber elementos

\footnotetext{
${ }^{1}$ Segundo Mondada (1994), os objetos de discurso caracterizam-se por se constituírem progressivamente em sua configuração textual-discursiva, enriquecendo-se com novos aspectos e propriedades. Assim, tais objetos não são os objetos do mundo natural ou biossocial, mas implicam diferentes sentidos que emprestamos a tais objetos na relação que estabelecemos socialmente com eles. Por essa perspectiva, os objetos do universo biossocial são reconstruídos em linguagem, o que implica novas predicações e recategorizações acerca de seres, fenômenos, coisas e ações.

${ }^{2} \mathrm{O}$ conceito de repredicação significa, no contexto deste trabalho, a atribuição de diferentes qualificações conceituais para o mesmo referente, considerando o modo como esse referente é veiculado na progressão tópico-temática de um determinado texto.
} 
discursivos e simbólicos já situados nas lendas tradicionais, para os quais empresta significações diferentes, "destoantes" e, até mesmo, contrapostas.

São 17 narrativas, divididas em quatro blocos, referentes aos quatro personagens lendários acima referidos que possuem características temático-discursivas em comum. Dentre estas, aponto algumas, como: (i) afiliação a elementos inscritos no universo lendário da Amazônia; (ii) inserção de elementos transgressivos e/ou diferenciados em relação aos elementos constitutivos das lendas tradicionais; (iii) desconstrução e/ou alteração de características simbólicas, discursivas ou semântico-discursivas dos personagens Boto, Cobra Grande, Matintaperera e Curupira e dos eventos ligados a eles, contidas tradicionalmente nas lendas, com agregação de características "inovadoras" e singulares quando do processo de construção de tais personagens e seus eventos nessas narrativas.

\section{Pressupostos teóricos}

Marcuschi (2008), ao postular a noção de linguagem como atividade sociocognitiva, afirma que a interação, a cultura, a experiência e os aspectos situacionais intervêm na determinação referencial. Nesse sentido, a predicação e a repredicação não são entendidas como meras nominalizações, mas como estratégias semântico-discursivas através das quais os sujeitos interagem ou dão sentido aos universos social e cultural, o que concede a essas atividades uma dinâmica e instabilidade características dos processos referenciais em toda a sua extensão.

Dada a natureza instável das categorias e considerando o modo como os objetos de discurso são (re)construídos nas interações, os processos de recategorização de referentes envolvem também novas predicações ou extensões destas, o que concede às atividades referenciais uma dinâmica própria. Os conceitos de categorização e recategorização estão baseados nas postulações de Marcuschi (2007), segundo as quais não existem categorias naturais, já que, para o autor, não existe um mundo naturalmente categorizado. Logo, a categorização do mundo implica diferentes sentidos por meio dos quais concebemos os elementos do mundo biossocial e cultural e que têm a ver com o modo como nos relacionamos com esses objetos. A recategorização implica, portanto, novos sentidos que emprestamos a tais objetos. Logo, em nível das atividades textuais, as repredicações contribuem não só para a renovação lexical do texto, como também para a atribuição de diferentes propriedades semântico-discursivas aos objetos de discurso que estão sendo carreados na atividade interacional/enunciativa. Nesse sentido, observe-se o que dizem Mondada e Dubois (2003, p. 29):

No seio das atividades discursivas, a instabilidade se manifesta em todos os níveis da organização linguística, indo das construções sintáticas às configurações de objetos de discurso. Esta instabilidade é particularmente observável na produção oral, podendo ser observada também nos textos escritos.

Nos processos de progressão temática e textual, a repredicação de referentes introduzidos e/ou reintroduzidos no texto reafirma o fato de que esses referentes podem ser renomeados, requalificados ou recaracterizados, o que se dá, obviamente, em razão da própria instabilidade a que estão submetidos no transcurso das ações sociointerativas, que também são instáveis, emergenciadas pelos contextos a que estão atreladas e imprevisíveis em seu processo de construção. 
Ao tratar os fatores de coerência, Koch (2004, p. 44) afirma que

[...] o critério da relevância exige que o conjunto de enunciados que compõem o texto seja relevante para um mesmo tópico discursivo, isto é, que os enunciados sejam interpretáveis como predicando algo sobre um mesmo tema [...]. Assim, a relevância não se dá linearmente entre pares de enunciados, mas entre conjuntos de enunciados e um tópico discursivo.

No âmbito da progressão textual, Koch (2006) destaca que, no processo de interdependência entre as partes do texto, os mecanismos de sequenciação constituintes da língua pressupõem encadeamento tópico, daí constatar-se, nesse encadeamento, processos em que os referentes são predicados e repredicados, contribuindo assim para a própria condução tópica dos sentidos em mobilização no texto. Em termos de continuidade tópica, Koch (2008) faz referência à relevância, postulando-a como proeminência de um conjunto de referentes em determinados segmentos textuais, em razão da posição focal de que se investem esses elementos no processo de construção do texto, o que implica, consequentemente, atividades de predicação e repredicação de tais elementos.

Embora as atividades de repredicação não impliquem também em recategorizações, elas são produtivas porque desvelam diferentes facetas ou aspectos de um mesmo referente, que continua mantendo suas propriedades básicas e originárias. Nesse sentido, a repredicação consiste numa espécie de prisma ou ângulo qualificativo por meio do qual um dado referente pode ser visto no processo de construção da referência ou da correferência. Logo, as estratégias de repredicação constituem elementos de superfície por meio dos quais os itens da cadeia referencial são minimamente alterados ou modificados, mantendo-se em consonância e/ou em relevância os sentidos inerentes ao tópico em construção.

Podemos então dizer que o ato de repredicar não altera ou desintegra as relações de continuidade temática e discursiva existentes entre os itens referenciais que compõem um determinado quadro de referência contido num texto, pois o objetivo, nesse caso, é reforçar ou intensificar o conteúdo expresso por esses itens, ou mesmo inserir qualificadores que sejam mais adequados à identificação de certos referentes.

Por fim, é coerente creditar que as atividades de repredicação, enquanto recursos de ajustes de sentido de itens lexicais em relação a certos referentes, constituem formas de alinhamento cada vez mais crescentes de elementos semântico-discursivos no que concerne às intenções intercomunicativas dos sujeitos dentro do quadro de referência requerido por cada uma das diversas produções textuais.

\section{Análise do corpus}

A função textual-discursiva das (re)predicações pode operar no sentido de dar mais consistência e pertinência à construção dos referentes (personagens), os quais o produtor textual quer enfocar no texto, tendo em vista os objetivos interacionais que estão sendo carreados no decorrer da ação verbal. Desse modo, (re)predicar é sempre instanciar qualificações associadas às formas de existência de determinados referentes, os quais, no caso das histórias analisadas, de certa forma, já preexistem no universo lendário amazônico, no próprio contexto em que tais histórias são produzidas e circulam. 
Seguem-se os exemplos acerca da repredicação de referentes que dizem respeito a personagens afiliados ao lendário:

(1) [...] Todo mundo estava silencioso, concentrado em seu João para ouvir o fim da história. Ele continuou.

- No dia seguinte, acordei pensando. Será que matei o cara? Ou será que só feri? Mas, neste caso, eu não vi ele sair nadando... Quando chego na porta da frente da casa, que vejo na beira?

Ninguém nem respirava. Seu João fez suspense, olhando para cada um dos que estavam no bar ouvindo a história. E concluiu.

- Era um Boto. Um enorme de um Boto, morto, bem defronte de meu barraco, com meu arpão enterrado bem no meio do corpo.

Os presentes se entreolharam, surpresos. E seu João, novamente aborrecido, cenho franzido:

- Tão vendo? Tão vendo por que eu não queria contar? Hoje ninguém acredita nisto.

E virando-se para mim: - Principalmente vocês que são da cidade...! (MONTEIRO, 2000c, p. 10).

[...] E lá um dia... não demorou muito, mas quando menos esperavam, eis que... Mas faltou dizer ainda que a madrinha do menino fizera uma autêntica preparação. Vivia com o pano de batismo do menino seguro na sua vestimenta, bem como estava com uma faca sempre por perto. Não queria que, quando a cobra aparecesse, ela estivesse desprevenida, mesmo porque o pajé dissera que haveria única oportunidade.

E lá um dia... não demorou muito... quando menos esperavam, eis que uma cobra, tal como o pajé dissera, aparece para a madrinha do menino, bem no meio da sala. Não era uma cobra grande, pelo contrário devia ter no máximo uns sessenta centímetros. Mas a madrinha, como se estivesse hipnotizada, ficou olhando a cobra atravessar a sala, sair pela porta da rua em direção ao mato da frente e sumir, sem que conseguisse se mexer, quanto mais lançar o pano de batismo do menino em cima da cobra e ainda cortar-lhe o rabo... [...]. (MONTEIRO, 2000b, p. 17-18).

(3) [...] Quando chegou de noite, assim que a Matinta começou a assobiar, quando se ouviu - Fiiiiiiittt...!

O pajé saiu da casa em que estava, começou a fazer suas orações, pegou as duas cuias pitinga e colocou em cima da sandália emborcada. Era a fórmula para amarrar Matinta Perera!

Naquela noite ouviu-se ainda um assobio cortado pela metade e um barulho assim como se fosse um pato se debatendo em cima de um galho de uma árvore próxima. Ninguém foi olhar, esperando a manhã seguinte...

Ao amanhecer o pajé chamou João Piraqueira para ir ver a Matinta amarrada pela fórmula...

Veja só o que é o destino!

O pajé disse para o rapaz:

- Agora vamos saber quem é a Matinta Perera do Rio Maiuatá!

Quando chegaram no local, sobre um galho de uma árvore próxima às duas cuias pitinga em cima da sandália emborcada, estava uma mulher que dali não conseguia se mexer, como se estivesse amarrada no galho. O pajé disse para João Piraqueira:

- Esta é a Matinta Perera que estava perturbando vocês...! [...]. (MONTEIRO, 2007, p. 16-18).

(4) [...] Apesar de já ter viajado em muitos rios, de ter penetrado em matas virgens no interior do Pará e de quase toda a Amazônia, para tristeza minha, não, eu nunca tinha me encontrado ou menos visto de longe o famoso defensor das florestas. $\mathrm{E}$ foi um tanto constrangido que respondi:

- Não, nunca vi o Curupira. As descrições que faço são aquelas que ouço das histórias que me contam.

$[\ldots]$

Aí o primo Eraldo gritou:

- É o Curupira...!

Suzy desmaiou.

O pequeno ser não se mexeu do lugar. Seus primos depois contaram que ficou olhando fixamente nos olhos dos dois, ao mesmo tempo. Eles ficaram imobilizados, não conseguiram se mexer, como se hipnotizados estivessem. Ficaram um bom tempo assim. Curupira olhando, Suzy desmaiada, e os dois primos sem poder se mexer, mas o Curupira não fez nada. Depois de algum tempo, tal como chegara, se foi, entrando na mata...! [...]. (MONTEIRO, 2002, p. 11-14). 
Os quatro exemplos supracitados apresentam repredicações de entidades que se constituem como centrais no enredo que está sendo construído pelo produtor do texto. Essas repredicações partem de nomeações básicas dos referentes, que passam a ser modificadas no curso da progressão textual, de modo a caracterizar com mais propriedade esses elementos, apresentando-os de forma mais completa ou apropriada ao tópico aí veiculado.

Tomando por base os exemplos em pauta, podemos observar, no caso do exemplo 1, que o referente boto não vem expresso ou lexicalizado no decurso de quase $85 \%$ do enredo e do texto, pois somente em um dos últimos parágrafos da narrativa (cf. narrativa completa) é que esse referente passa a ser nomeado. Assim, após o procedimento stand by de não colocação do referente pretendido, o produtor coloca-o, finalmente, em foco na cadeia referencial, requalificando-o logo em seguida:

“- Era um Boto. Um enorme de um Boto, morto, bem defronte de meu barraco, com meu arpão enterrado bem no meio do corpo".

No entanto, essa estratégia de requalificação do referente por meio das expressões nominais indefinidas um enorme de um Boto e morto é antecedida pelo processo de introdução de um novo objeto-de-discurso, que se institui como essencial para o tópico que está sendo posto em ação, com o qual a história se configura em termos interacionais. Logo, a expressão referencial um boto constitui um novo objeto de discurso que tem a propriedade discursiva e textual de dar corpo ao que é objeto principal da atividade tópica, apresentando-se como um elemento "inusitado", mas, por outro lado, possível de ser resgatado na memória discursiva do leitor.

No exemplo 2, a expressão nominal definida a cobra passa a ser repredicada por meio da expressão nominal indefinida: "não era uma Cobra Grande", que, consequentemente, é referendada por meio da expressão verbal "devia ter no máximo uns sessenta centímetros", cujo núcleo repredicador relativo ao elemento básico, uma cobra, que inicialmente havia sido predicada por meio da expressão "aparece para a madrinha do menino bem no meio da sala", é repredicada por meio do enunciado verbal "devia ter no máximo uns sessenta centímetros".

No que tange ao exemplo 3, observa-se que o referente Matintaperera vem inicialmente manifesto por meio das expressões nominais a Matinta (definida) e Matinta Perera (indefinida), sendo mais abaixo repredicado nas expressões A Matinta amarrada e a Matinta Perera do Rio Maiuatá. Como se pode verificar, a primeira repredicação se dá através de uma proposição nominal breve, cujo núcleo predicador é a forma nominal amarrada. Já a segunda repredicação se realiza por meio de uma proposição nominal mais longa: do Rio Maiuatá, com valor locativo, tendo também uma função contextualizadora e identificadora mais estrita em relação à personagem que está sendo descrita. Nesse sentido, discuto aqui o papel da repredicação como fator capaz de caracterizar os referentes que estão em jogo numa determinada ação verbal.

O exemplo 4 apresenta como elemento repredicado a entidade Curupira que, no preâmbulo da narrativa, passa a ser denominado de ofamoso defensor das florestas - uma forma de repredicação do personagem supracitado, que aí se realiza por meio de uma estrutura nominal definida mais complexa, sendo depois "reatualizada" pela expressão nominal o Curupira, que, por sua vez, sofre uma nova predicação por meio da nominação o pequeno ser. Os dois tipos de repredicação do referente mais prototípico (o Curupira) atuam no cotexto de forma diferenciada, pois enquanto a primeira repredicação tem uma 
ligação de sentido mais próxima ou associada à figura do Curupira, por força das próprias estruturas conceituais que envolvem esse personagem afiliado ao lendário, a segunda possui uma significação mais ampla e geral, estando mais presa à própria natureza ou especificidade do cotexto em que é enunciada, no qual é tomada como elemento de referência em relação ao personagem mencionado. Logo, fora deste contexto específico, poderia ter um significado referencial e predicativo bem diverso.

Conforme posto nos quatro exemplos, os processos de repredicação de referentes de entidades afiliadas ao lendário instauram revalorações no que concerne ao estabelecimento e à construção da referência que, no caso dos textos em estudo, têm a função não somente renomeadora de per se, mas, sobretudo, um papel reconstrutor/delineador mais preciso e refinado acerca da constitutividade inerente a certos personagens, como é o caso dos aqui analisados. Nesse âmbito, as repredicações atuam não só no sentido de reconstituição dos entes afiliados ao lendário em estudo, mas na perspectiva de reconstituição das crenças relativas a esses entes, que, de uma forma ou de outra, estão reconstruídas nos textos das narrativas de Monteiro.

Dada a quantidade de repredicações presentes no corpus, apontamos mais cinco exemplos relativos a essa estratégia, que, nesse caso, dizem respeito a outros referentes contidos nas histórias sob investigação. Vejam-se os exemplos:

[...] Um dia, acompanhado de amigos, pegou o barco e foi a uma festa. Benevenuto ia falando que não acreditava nas histórias que contavam. E falou de novo:

- Eu até queria ver uma encantada destas... Mas que fosse muito bonita...

Foram pra festa e dançaram, dançaram, dançaram... Quando terminou, Benevenuto separou-se dos demais e dirigiu-se para o barco sozinho. Ao se aproximar, viu aquela linda mulher, loura e muito bem feita de corpo, que se insinuou. Benevenuto era mulherengo, mas desta vez ficou receoso. E a mulher foi se jogando pra cima dele. Benevenuto de repente desconfiou e pensou nas coisas que havia falado e nos desafios que tinha feito.

"- Pois eu queria que me aparecesse uma encantada destas. Mas que fosse uma mulher muito bonita..."

E ali estava. Benevenuto ficou com medo, muito medo. Ele, Benevenuto, mulherengo e com medo de mulher. Podia um negócio deste? Mas estava. A mulher avançando, ele recuando, até que ela tentou agarrá-lo... Benevenuto sempre usava um pequeno facão no fundo do barco e que naquele instante estava em suas mãos. Com o medo que estava, não pensou duas vezes: passou o facão na cintura da mulher, que caiu na beira da praia, próximo ao barco, morta...! [...]. (MONTEIRO, 2000b, p. 19-20).

(6) [...] E o velho João começou sua narrativa.

- Olhe, moço, já fazem uns tantos anos... Foi logo que me casei com a Mundica. Ela era uma cabocla nova, bonita e bem feita de corpo. Nós tinha casado e estava vivendo no meu barraco na beira do rio... Vida de pobre, sabe como é né? Não se vivia com riqueza, mas o de comê nunca faltou... E a gente se gostava de verdade e ia levando a vida feliz... Um dia... - a fisionomia do caboclo foi ficando cerrada - um dia, seu moço, vi minha Mundica meio arredia, como quem tá escondendo alguma coisa... Fiquei desconfiado, mas não disse nada, fiquei só observando o jeito dela. Notava que Mundica não era a mesma e chamei ela pr'uma conversa séria... Que que tá havendo, mulher? Por que tu anda desse jeito? Tu não é mais a mesma... Primeiro ela ficou calada, depois, choramingando, foi que Mundica falou:

- Sabe? É um homem! Um desgraçado que vive rondando nossa casa de noite... Tu ainda não visse, não?

- Não, não vi nada não. E por que tu não me disseste logo? Quem é esse filho duma égua?

- Eu não sei, meu filho, juro que não sei... Quando tu sai à noite que vai pescar, eu fecho toda casa, e ele fica rondando, rondando...

- Ah! se eu pego este filho duma vaca! Ele só vem à noite e quando saio?

- É isto mesmo, meu filho...! 
E seu João continuou:

- Não disse nada. Na minha cabeça - me perdôem vocês, me perdoe Deus - só vinha vontade de matar. E eu ficava pensando quem poderia ser que tava querendo dar em cima da minha mulher... No dia seguinte anunciei bem cedo que ia pra pesca. E saí mesmo.

À medida que ia falando, seu João, como se estivesse muito aborrecido, ia franzindo cada vez mais a testa e o cenho. Procurou se acalmar. [...]. (MONTEIRO, 2000c, p. 8-9).

[...] Um dos tripulantes, o Marujo, porém, saltou e começou a andar por dentro da mata. Anda aqui, ali e acolá, afastou-se do local onde os passageiros estavam acampados. Sempre examinando o local, ouviu como que o cair de água de alguém que estivesse tomando banho de cuia. Aí viu que estava próximo a um igarapé e se aproximou bem devagar, sorrateiramente. Pensava quem poderia ser.

- Será que é uma das passageiras?

Sem fazer barulho, aproximou-se mais, sempre se escondendo atrás das moitas. Quando estava bem perto, o que viu? Era uma moça loira, cabelos compridos, branca, sentada num tronco atravessado no igarapé, apanhando água com uma cuia e tomando banho inteiramente nua. Marujo ficou extasiado com aquela bela visão. A moça estava de costas para ele e, por isso mesmo, ficou surpreso e espantado quando ouviu:

- Ei, moço! O que o senhor está fazendo aí?

Ela não tinha se virado, não tinha olhado pra ele, daí a razão do espanto. [...] (MONTEIRO, 2000b, p. 23).

(8) [...] Quase que a ladainha acaba: todos praticamente correram para ver do que se tratava e, ao chegarem no dito tucumanzeiro, qual a surpresa: lá estava D. Chiquinha, conhecida lavradora do local, toda ferida, gritando muito, pedindo socorro, que a livrassem dos espinhos e das palmas do tucumanzeiro... Foi uma luta para tirarem D. Chiquinha lá de cima, o que só foi conseguido com muita dificuldade... E, por mais incrível que pareça, D. Chiquinha, a Matinta Perera de Campo de Baixo, sobreviveu... Mas deixou uma lição: Lobisomem ou Matinta Perera não podem ver coisas sagradas nem ouvir nem pensar o nome de Deus, que o encanto se desfaz na hora! E foi o que aconteceu com D. Chiquinha: ela, como Matinta Perera, estava cumprindo a sua sina, porém, ao sobrevoar a ladainha de São Benedito, olhou para baixo, ouviu o nome de Deus, o encanto se desfez, e já em forma de gente, despencou lá de cima, caindo no tucumanzeiro... (MONTEIRO, 2000c, p. 14)

(9) [...] "Nosso roçado era muito grande e nele trabalhavam todos os membros da minha família: meus pais, meus irmãos e cunhados. Entre estes, havia um, de nome Ulisses, que era um rapaz muito trabalhador. Numa tarde, estávamos todos nós para um lado do roçado, e Ulisses, sozinho, estava trabalhando noutro local, um pouco distante. Eram cerca de seis horas da tarde quando ouvimos gritos de socorro. A voz não enganava: era de Ulisses. Corremos na direção dos gritos e ali encontramos Ulisses apavorado, sem conseguir sair de onde se encontrava. Mal conseguia falar. Quando pôde dizer alguma coisa, contou que estava trabalhando, quando sentiu como que uma presença perto de si. Ao olhar em torno, deu com aquele caboclinho bem perto. Espantou-se. Mais ainda porque não ouvira nenhum sinal de sua aproximação. Entretanto o caboclinho estava ali, a olhá-lo atentamente. Todo nu, o corpo moreno parecia feito de lascas de madeira marrom, como se fosse uma proteção...

$[\ldots]$

Começamos a fazer perguntas, como era o Curupira, porque embora nós sentíssemos sua presença, nunca nenhum de nós o tinha visto. Só ouvíamos as histórias, inclusive de suas mundiações, quando fazia os caçadores se perderem no mato...

Ulisses respondia a todas as perguntas: dizia que era um curumim (menino), um caboclinho mesmo, que estava nu, que seu corpo parecia de pequenas placas de alguma coisa como se fosse madeira de cor marrom... Quando perguntávamos se tinha mesmo os pés virados para trás, Ulisses ria e não respondia nem que sim, nem que não... Mas ele levou um grande susto. A história se espalhou pela Serra de Parintins e durante muito tempo se falou no encontro com o Curupira..." (MONTEIRO, 2000a, p. 20-21). 
Considerando os trechos em exemplo, apresento algumas estratégias de repredicação de referentes:

(i) Ao se aproximar, viu aquela linda mulher, loura e muito bem feita de corpo;

(ii) Ele, Benevenuto, mulherengo e com medo de mulher;

(iii) Foi logo que me casei com a Mundica. Ela era uma cabocla nova, bonita e bem feita de corpo;

(iv) É um homem, um desgraçado que vive rodando nossa casa de noite... [...] E por que tu não disseste logo? Quem é esse filho duma égua? [...] - Ah! se eu pego este filho duma vaca!

(v) Quando estava bem perto, o que viu? Era uma moça loira, cabelos compridos, branca, sentada num tronco atravessado no igarapé;

(vi) Ao chegarem no dito tucumanzeiro, qual a surpresa: lá estava $D$. Chiquinha, conhecida lavradora do local, toda ferida, gritando muito, pedindo socorro... [...] E, por mais incrível que pareça, D. Chiquinha, a Matinta Perera de Campo de Baixo, sobreviveu...

(vii) Entre estes, havia um, de nome Ulisses, que era um rapaz muito trabalhador... [...] Ulisses respondia a todas as perguntas: dizia que era um curumim (menino), um caboclinho mesmo, que estava nu, que seu corpo parecia de pequenas placas de alguma coisa como se fosse de madeira de cor marrom...

A partir dos itens apresentados, retirados de excertos das narrativas, podemos observar que as repredicações dos referentes em destaque interligam-se aos processos de construção das entidades em estudo, afiliadas ao universo lendário, que passam a constituir elementos coadjuvantes importantes para a própria relevância textualdiscursiva inerente às produções em análise. Dentre os itens apontados, se tomamos o (i), o (iii) e o (iv), podemos observar que, em (i), o elemento que é repredicado, aquela linda mulher, se realiza por meio das expressões: loura e muito bem feita de corpo. Estas expressões têm a propriedade de reconceituar ou redefinir com mais detalhes e pertinência o referente antes introduzido. Assim, os elementos repredicadores aí expressos não são meros acessórios descritivos e estilísticos que "enfeitam" a construção de um determinado personagem, mas são recursos textuais necessários a essa própria construção, proporcionando uma maior visibilidade ao ente que está sendo colocado em foco durante o processo narrativo. Logo, dado esse pressuposto, e considerando, nesse âmbito, o fenômeno da repredicação, é válido postular a importância das sequências textuais descritivas para o processo de construção de personagens e eventos relativos a eles. Tais sequências têm também papel relevante no que concerne à elaboração de uma espécie de "performance" ou caráter desses personagens, mais especificamente no que tange ao seu trânsito e/ou mobilização dentro da atividade narrativa, o que se constitui como pertinente às narrativas estudadas neste trabalho; tendo-se em conta as diferentes facetas ou qualificações de que são possuidoras as entidades e fatos relacionados ao lendário. 
No caso do item (iii), embora a repredicação opere de modo mais ou menos similar ao (i), ela parte de uma expressão nominal definida na qual o referente básico é um nome próprio, já conhecido do narrador, que agora, por meio do processo de repredicação, vem a ser reconstruído ou desvelado melhor para o leitor. Assim, a expressão nominal indefinida uma cabocla nova não indefine, na verdade, o referente, mas concede-lhe um perfil mais "completo" na retomada anafórica aí implementada.

Em (iv), o referente introduzido é um homem, o qual, atravessado por um processo narrativo de suspense (plot), que se realiza por meio de uma sequência catafórica - indo esta desembocar num referente final principal ainda a ser posto na cadeia textual - passa a ser repredicado pelas seguintes expressões: um desgraçado; esse filho duma égua; este filho duma vaca. Logo, como se pode observar, a sequência catafórica repredicadora vai do mais indefinido para o mais definido, já que cada uma das expressões é encabeçada por um determinante que aponta para essa estratégia, o que corrobora, mais uma vez, o fato de que a repredicação constitui um recurso textual cuja função é retratar com mais precisão um determinado referente já colocado antes no texto.

Como se pôde observar nos exemplos, as atividades de repredicação contribuem para uma melhor caracterização dos referentes na estrutura referencial das narrativas, adequando-se estes aos objetivos intencionados pelo produtor do texto e ao caráter da ação sociodiscursiva em construção.

Observe-se a tabela abaixo relativa às ocorrências de estratégias de Repredicação de Referentes:

Tabela 1. Estratégias de repredicação de referentes que contribuem para a progressão temática do texto

\begin{tabular}{l|c|c|c|c|c}
\hline \multicolumn{1}{c|}{$\begin{array}{c}\text { Narrativas referentes aos } \\
\text { personagens lendários }\end{array}$} & Boto & Cobra & Matintaperera & Curupira & Total \\
\hline Número de Narrativas & 04 & 05 & 05 & 03 & 17 \\
\hline $\begin{array}{l}\text { Ocorrências de elementos } \\
\text { repredicadores }\end{array}$ & 24 & 92 & 46 & 27 & 189 \\
\hline Percentual (\%) & 12,70 & 48,68 & 24,34 & 14,28 & 100 \\
\hline
\end{tabular}

Fonte: Autor do artigo, a partir de dados apresentados na Revista Visagens, Assombrações e Encantamentos da Amazônia.

De acordo com os dados expressos na tabela, observamos o total de 189 ocorrências de elementos repredicadores de referentes. Logo, considerando as 17 (dezessete) narrativas analisadas, tem-se uma média de 11,12 ocorrências por narrativa, o que vem a se constituir como um dado significativo em termos de incidência dos mencionados elementos. Já em se tratando de percentuais, detectamos um percentual mais elevado dessas ocorrências nas narrativas de Cobra; no caso, 48,68\%, tendo-se, em segundo lugar, as narrativas de Matintaperera, com 24,34\%. Aparecem, em terceiro lugar, as narrativas de Curupira, com 14,28\% e, por último, as de Boto, com 12,70\%.

Assim, o total de ocorrências dos referidos elementos apresenta-se como relevante, mais precisamente como recursos textual-discursivos ligados aos processos de construção das atividades referenciais. 


\section{Considerações finais}

Considerando os percentuais relativos à repredicação de referentes, observamos que as narrativas de Cobra são as que mais apresentaram a estratégia supracitada, estando, em segundo lugar, as narrativas de Matintaperera. Isso pode se dar em razão de essas entidades lendárias serem as que mais se metamorfoseiam, estando, portanto, mais suscetíveis a processos de repredicação. Assim, no ambiente cultural em que as narrativas de Cobra são (re)contadas, esta é detentora de diversos e variados processos metamórficos e predicacionais e/ou extensivos, com desdobramentos concernentes ao uso de estratégias qualificadoras nas atividades textual-discursivas em que se apresenta como personagem. É o que acontece também com a Matinta, na qual os citados processos de transmutação e qualificação são bastante variados e heterogêneos, podendo, nesse caso, uma velha transformar-se em porco (a), cavalo, pássaro, etc. Tem-se em conta também, nesse âmbito, a relação entre esse personagem e a figura da bruxa, bastante recorrente no contexto cultural em que são (re)contadas narrativas referentes a essa entidade. No caso do Boto, cujo percentual de repredicações foi o menor, isto possivelmente se deva em razão do fato de que se transforma somente em homem ou, no caso das narrativas analisadas, também em mulher, não havendo, portanto, no universo de contação das histórias de Boto, muitas alternativas relativas ao processo metamórfico. Consequentemente, também não há formas de qualificação mais variadas e díspares quando da construção de atividades textual-discursivas em que se constitui como personagem.

Dado o exposto e considerando, neste âmbito, o que os dados mostraram em termos de estratégias de repredicação de referentes e progressão temática do texto, postulo que os referentes são instáveis e dinâmicos, demandando processos constantes de reconstrução ou transformação destes nas atividades textual-referenciais. Por essa perspectiva, as atividades de (re)construção desses referentes são resultados de contextos culturais situados e de práticas sociais aí mobilizadas. Acrescente-se que as narrativas em análise evidenciaram o fato de que as estratégias de repredicação podem demarcar ou indicializar significados relacionados a formas de transgressão e/ou reconstrução de elementos inscritos/pressituados no universo lendário, no caso em estudo, no universo lendário amazônico. Nesse sentido, as expressões referencial-repredicadoras se apresentam, de acordo com as análises realizadas, como importantes instrumentos textual-discursivos por meio dos quais o produtor das narrativas em análise subverte e/ou altera significados previamente construídos nas construções lendárias, operando significações extensivas, diferentes ou mesmo distanciadas dos quadros de referência em circulação no ambiente amazônico, no qual as narrativas em questão são (re)contadas. Por outro lado, essas produções vão muito além de artefatos puramente ficcionais, pois incorporam características textuais e sociodiscursivas que se apresentam como reconstituições de experiências coletivas e particulares próprias dos sujeitos que se inserem no mundo amazônico.

\section{REFERÊNCIAS}

KOCH, I. G. V. Introdução à linguística textual. São Paulo: Martins Fontes, 2004. . Desvendando os segredos do texto. São Paulo: Cortez, 2006. . As tramas do texto. Rio de Janeiro: Nova Fronteira, 2008. 
MARCUSCHI, L. A. Cognição, linguagem e práticas interacionais. Rio de Janeiro: Lucerna, 2007.

Produção textual, análise de gêneros e compreensão. São Paulo: Parábola Editorial, 2008.

MONDADA, L. Verbalisation de l'espace et fabrication du savoir: approche linguistique da la construction des objets de discours. Lausanne: Université de Lausanne, Thèse, 1994.

MONDADA, L.; DUBOIS, D. Construção dos objetos de discurso e categorização: uma abordagem dos processos de referenciação. In: CAVALCANTE, M. M.; RODRIGUES, B. B.; CIULlA, A. (Org.). Referenciação. São Paulo: Contexto, 2003.

MONTEIRO, W. Encontro com o curupira. In: Visagens e Assombrações $e$ Encantamentos da Amazônia. 3. ed. n. 2, Ano I. Belém: Smith - Produções Gráficas. 2000a. p. 20-21.

. Visagens e Assombrações e Encantamentos da Amazônia. 2. ed. n. 3, Ano I. Belém: Smith - Produções Gráficas, 2000b.

. Visagens e Assombrações e Encantamentos da Amazônia. 2. ed. n. 5, Ano II. Belém: Smith - Produções Gráficas, 2000c.

Suzy e o curupira. In: Visagens e Assombrações e Encantamentos da Amazônia.

2. ed. n. 7, Ano III. Belém: Smith - Produções Gráficas, 2002. p. 11-14.

A tia Podó. In: Visagens e Assombrações e Encantamentos da Amazônia. 2. ed. n. 8, Ano IV. Belém: Smith - Produções Gráficas, 2007. p. 15-18.

Recebido em: 10/08/2016

Aprovado em: 10/01/2017 